Copyright (C) 2021 University of Bucharest Printed in Romania. All rights reserved

ISSN print: $1224-5984$

ISSN online: $2248-3942$
Rom Biotechnol Lett. 2021; 26(5): 2926-2935 doi: $10.25083 / \mathrm{rbl} / 26.5 / 2926.2935$

Received for publication, May, 18, 2021

Accepted, June, 7, 2021

Original paper

\title{
Identification of Lactic Acid Bacteria in the corn stalk Fermentation by Fluorescence Quantitative PCR
}

\author{
HUAYOU CHEN ${ }^{1,2, *}$, KANGTAO CAI ${ }^{1}$, LINGYU KANG ${ }^{1}$,TINGTING LI ${ }^{1}$, \\ XIAOYU LIANG ${ }^{1}$, XINYU HENG ${ }^{1}$
}

${ }^{1}$ Institute of Life Science, Jiangsu University, Zhenjiang 212013, China

${ }^{2}$ National Key Laboratory of Biochemical Engineering, Institute of Process Engineering, Chinese Academy of Sciences, Beijing, 10090, China

\begin{abstract}
Lactic acid bacteria play an important role in the fermentation of biological feed. In this experiment, Lactobacillus plantarum, Lactobacillus acidophilus, Bifidobacterium longum, Lactobacillus casei and Lactobacillus rhamnosus were used to ferment corn stalk by single and mixed bacteria. The changes of Lactobacillus flora during fermentation were analyzed by fluorescence quantitative PCR. The results showed that the maximum number of lactic acid bacteria appeared on the $7^{\text {th }}$ day of mixed fermentation, and the total bacteria content could be significantly increased by adding five kinds of lactic acid bacteria at the same time, and the number of each bacteria in mixed fermentation was close to that measured by single fermentation, which indicated that these five kinds of lactic acid bacteria could cooperate during fermentation and help to improve the quality of stalk fermented feed.
\end{abstract}

Keywords Fluorescence Quantitative PCR; Lactic acid bacteria; Flora change

To cite this article: CHEN H, CAI K, KANG L, LI T, LIANG X, HENG X. Identification of Lactic Acid Bacteria in the corn stalk Fermentation by Fluorescence Quantitative PCR. Rom Biotechnol Lett. 2021; 26(5): 2926-2935. DOI: 10.25083/rbl/26.5/2926-2935

*Corresponding author: HUAYOU CHEN, Institute of Life Science, Jiangsu University, Zhenjiang 212013, China E-mail: hyc@ujs.edu.cn 


\section{Introduction}

Microbial strain is the key to ferment biological feed by adding microbial feed additives (Liu et al.2019b), because the growth and metabolism of different strains will be different. Most of the reported fermentation methods of bio-feed also adopt the method of co-fermentation of compound strains (Yan et al. 2019). The metabolites produced by probiotic fermentation of feed can effectively prevent the colonization of Gram-negative bacteria in intestine (Lee et al. 2019). Using multi-strain mixed fermentation for bio-feed production is much better than single strain fermentation, because after mixed fermentation of different strains, the differences between them can be used to compensate for each other, and mutually beneficial symbiosis can be achieved (Liu et al. 2019a). For example, Yao et al.(Yao et al. 2018) invented a kind of bio-feed and its production method, which utilized the co-solid-state fermentation tank of Bacillus subtilis and yeast to make it a nutritious animal feed; Lan et al.(Lan and Kim 2019) fermented feed by Bacillus subtilis and Bacillus licheniformis, which improved animal growth performance and animal digestibility of nutrients.

Lactic acid bacteria play an important role in the fermentation of corn stalk bio-feed because anaerobic fermentation is carried out after encapsulation. Bacteria and metabolites of lactic acid bacteria can resist the invasion of pathogenic bacteria to intestinal wall. In addition, both living and dead lactic acid bacteria contain beneficial components of fermented biological feed, which can improve the quality of fermented feed (Ou et al. 2011). At the same time, Lactobacillus as the dominant bacteria in animal intestinal tract, fermentation can produce a large amount of lactic acid(Giraffa et al. 2010), acetic acid and some volatile fatty acids, which can reduce the $\mathrm{pH}$ of animal digestive tract, thus inhibiting the growth of harmful bacteria and reducing the incidence of animal intestinal diseases (Markkinen et al. 2019); Lactobacillus can not only inhibit the growth of pathogenic bacteria, but also adhere to the intestinal cells of animals and play a spaceoccupying protective role (Mousavi and Mousavi 2019). Among them, Lactobacillus acidophilus has the functions of regulating intestinal flora, improving immunity, producing more acid and reducing the activity of toxic microorganisms (Sharma et al. 2018); Lactobacillus plantarum is a lactic acid bacteria existing in fermented products such as bread. Adding Lactobacillus plantarum to fermented feed can produce amylase, which can make up for the shortcomings of other lactic acid bacteria that generally do not produce amylase (Heo et al. 2018); Lactobacillus casei can tolerate enzymes in the mouth, low pH gastric juice environment (Jangra et al. 2019), inhibit the growth of spoilage bacteria and pathogenic bacteria in some foods, but it does not affect the appearance of food, and even optimize food characteristics (Fontana et al. 2018). Therefore, adding Lactobacillus casei to feed as a starter can help feed quality production, it also plays an active role in preservation and preservation of feed during storage (Guo et al. 2018); Lactobacillus rhamnosus can enhance the immune function of the body, reduce and eliminate food toxins, and treat intestinal dysbacteriosis diarrhea (Yadav et al. 2018); Bifidobacterium longum is a specific anaerobic bacterium, it can inhibit the growth of pathogenic bacteria through its own or secreted metabolites (Elsanhoty et al. 2017). In the fermentation process, it maintains its own advantage of bacteria, interacts with other bacteria and adjusts the relationship between the whole bacteria, so as to achieve the goal of maintaining the balance of bacteria (Slacanac et al. 2005).

This paper mainly studies the evolution of microflora during the fermentation of corn stalk by Lactobacillus plantarum, Lactobacillus acidophilus, Bifidobacterium longum, Lactobacillus casei and Lactobacillus rhamnosus, so as to provide reference for the high quality production of corn stalk biological feed and other raw materials.

\section{Materials and Methods}

\section{Experimental strains and raw materials}

Strains: Bacillus subtilis CGMCC 1.1086, Saccharomyces cerevisiae CGMCC 2.1527, Lactobacillus plantarum CGMCC 1.557, Lactobacillus acidophilus CGMCC 1.2467, Bifidobacterium longum CGMCC 1.2186, Lactobacillus casei CGMCC 1.8727, Lactobacillus rhamnosus CGMCC 1.577, purchased from China General Microbial Species Preservation and Management Center (freeze-dried powder, stored at $4^{\circ} \mathrm{C}$ ).

Raw Material: Crushed corn stalk, dried at $45^{\circ} \mathrm{C}$ and sifted at 20 meshes, stored in dry environment.

Bacillus can tolerate high temperature, high pressure and acidic environment, at the same time, it has good activity of protease and cellulase, etc., which can break the cell wall of agricultural waste and promote the release of nutrients in straw. Yeast can produce abundant thallus protein and a small amount of alcohol to induce animal feeding. In addition, the addition of Bacillus and Yeast in the fermentation can continuously consume oxygen to create a good anaerobic fermentation environment for lactic acid bacteria.

\section{DNA extraction}

The standard strain freeze-dried powder was mixed with proper amount of sterile saline, inoculated in PDA solid medium, incubated in constant temperature incubator at $37^{\circ} \mathrm{C}$ for $24-48$ hours, then single colonies were selected by sterile inoculation ring and inoculated into LB medium, MRS medium and malt juice medium respectively, aerobic or anaerobic incubation at $37^{\circ} \mathrm{C}$ to activate the strains, until the $\mathrm{OD}_{600}$ of the strain is 0.8 . Fresh strains of standard strains were collected, and bacterial DNA was extracted by bacterial genome extraction kit (Shanghai Biotechnicians); yeast DNA was extracted by fungal genome extraction kit (Takara). The experimental steps were in accordance with the instructions. The PCR products were analyzed by $3 \%$ agarose gel electrophoresis and the quality and concentration of DNA were analyzed by ultraviolet spectrophotometer. 
Primer Design

The primer sequence (de Almeida et al. $\underline{2015}$ Gueimonde et al. 2004; Makino et al. 2010;
Borshchevskaya et al. 2013), amplified fragment size and annealing temperature used in this experiment are shown in Table 1 .

Table 1 Primer Sequence and Annealing Temperature

\begin{tabular}{|c|c|c|c|}
\hline Name of Strain & Primer Sequence $\left(5^{\prime}-3^{\prime}\right)$ & $\begin{array}{l}\text { Amplified } \\
\text { fragment size } \\
(\mathrm{bp})\end{array}$ & $\begin{array}{l}\text { Annealing } \\
\text { temperature } \\
\left({ }^{\circ} \mathrm{C}\right)\end{array}$ \\
\hline \multirow[t]{2}{*}{ Bacillus subtilis } & F: AAAATCCGCGCGTATCGTTG & 520 & 53.2 \\
\hline & R: CTCGGCCTGATTCGTATGCT & & \\
\hline \multirow[t]{2}{*}{ Saccharomyces cerevisiae } & F: GCGATAACGAACGAGACCCTAA & 225 & 53.2 \\
\hline & R: CCAGCACGACGGAGTTTCACAAGAT & & \\
\hline \multirow[t]{2}{*}{ Lactobacillus plantarum } & F: CAGCACTAGATACCGCCCTG & 211 & 53.2 \\
\hline & R : ATGTAGTGCCACGGTCGTTT & & \\
\hline \multirow[t]{2}{*}{ Lactobacillus acidophilus } & F: AGACACGGCCCAAACTCC & 231 & 52.6 \\
\hline & R: GACAACGCTTGCCACCTA & & \\
\hline \multirow[t]{2}{*}{ Bifidobacterium longum } & F: GATTCTGGCTCAGGATGAACGC & 231 & 52.6 \\
\hline & R: CTGATAGGACGCGACCCCAT & & \\
\hline \multirow[t]{3}{*}{ Lactobacillus casei } & F: & 133 & 52.6 \\
\hline & CTATAAGTAAGCTTTGATCCGGAGATTT & & \\
\hline & R: CTTCCTGCGGGTACTGAGATGT & & \\
\hline \multirow[t]{2}{*}{ Lactobacillus rhamnosus } & F: TGCTTGCATCTTGATTTAATTTTG & 317 & 52.6 \\
\hline & R: GTCCATTGTGGAAGATTCCC & & \\
\hline
\end{tabular}

\section{Primer Specificity Verification}

The conventional PCR reaction was performed by crossing the genomic DNA of each standard strain with primers (the reaction system is shown in Table 2), and the amplified products of PCR were analyzed by $3 \%$ agarose gel electrophoresis.

Tablel 2 Conventional PCR Reaction System

\begin{tabular}{lc}
\hline System Component & Volume $(\mu \mathrm{L})$ \\
\hline 10×PCR buffer & 5 \\
dNTP Mixture & 4 \\
Upstream primer & 2 \\
Downstream primer & 2 \\
DNA template & 1.5 \\
ddH ${ }_{2} \mathrm{O}$ & 35.25 \\
Taq enzyme & 0.25 \\
\hline
\end{tabular}




\section{Establishment of Standard Curve}

The obtained PCR products was subjected to gelatinization and recovery of the DNA fragment as a standard for Fluorescence quantitative PCR, and the $\mathrm{OD}_{260 / 280}$ value and concentration of DNA fragments were measured. The calculation formula was as follows: copy number $=$ DNA concentration $(\mathrm{ng} / \mu \mathrm{L}) \times 10^{-9} \times 6.023 \times 10^{23} /$ $(660 \times$ base number). The standard samples satisfying the purity requirement were diluted by 10 times series to $1 \times 10$ ${ }^{8} \sim 1 \times 10^{-2}$ copies $/ \mu \mathrm{L}$. The standard curve could be drawn by taking the logarithm of positive template as abscissa and the initial cycle number $(\mathrm{Ct})$ of fluorescent signals in the process of PCR reaction as ordinate.

Detection of bacterial flora in biological feed by fluorescence quantitative PCR

The diluted DNA samples were used as positive templates and the corresponding primers of each strain were used for quantitative fluorescence PCR. The reaction system of $20 \mathrm{~mL}$ is as follows:

Table 3 Fluorescence Quantitative PCR Reaction System

\begin{tabular}{lc}
\hline System Component & Volume $(\mu \mathrm{L})$ \\
\hline $\mathrm{SYBR}^{(\mathrm{R})}$ Green Realtime PCR Master & 10 \\
$\mathrm{ddH}_{2} \mathrm{O}$ & 6 \\
template & 2 \\
Upstream primer & 0.8 \\
Downstream primer & 0.8 \\
ROX & 0.4 \\
\hline
\end{tabular}

The reaction procedure was as follows: first, it was predenatured at $95^{\circ} \mathrm{C}$ for 30 seconds, then amplified at $95^{\circ} \mathrm{C}$ for 5 seconds and at $60^{\circ} \mathrm{C}$ for 31 seconds for 40 cycles. After the reaction, the fluorescence signal was recorded by heating to $95^{\circ} \mathrm{C} 15 \mathrm{~s}$, then to $60^{\circ} \mathrm{C} 1 \mathrm{~min}$, and then to $95^{\circ} \mathrm{C} 1 \mathrm{~s}$.

\section{Experimental Design}

The fermentation method adopted was a step-by-step fermentation, that is, adding Bacillus subtilis and Saccharomyces cerevisiae to aerobic fermentation for 12 hours, then adding lactic acid bacteria, immediately encapsulating and anaerobic fermentation. Six samples were set up, three replicates for each sample. The samples of $0 \mathrm{~d}, 1 \mathrm{~d}, 2 \mathrm{~d}, 3 \mathrm{~d}, 5 \mathrm{~d}, 7 \mathrm{~d}, 10 \mathrm{~d}, 15 \mathrm{~d}, 20 \mathrm{~d}, 25 \mathrm{~d}$ and $30 \mathrm{~d}$ after encapsulation were respectively taken for quantitative fluorescence PCR. The specific experimental design is shown in Table $\underline{4}$. The above experimental samples were designed to be repeated in three groups at different time periods.

The change of lactic acid bacteria flora in the process of stepwise fermentation without sterilization of raw materials was studied.

Table 4 Experimental materials and fermentation strains

\begin{tabular}{|c|c|c|c|}
\hline Samples & Raw Material & $\begin{array}{c}\text { Water } \\
\text { content }\end{array}$ & Fermentation Strain \\
\hline $\mathrm{A}$ & $\begin{array}{l}\text { Corn stalk } 80 \% \\
\text { Bran } 20 \%\end{array}$ & $35 \%$ & Bacillus subtilis, Saccharomyces cerevisiae, Lactobacillus plantarum \\
\hline B & $\begin{array}{l}\text { Corn stalk } 80 \% \\
\text { Bran } 20 \%\end{array}$ & $35 \%$ & Bacillus subtilis、Saccharomyces cerevisiae、Lactobacillus acidophilus \\
\hline $\mathrm{C}$ & $\begin{array}{l}\text { Corn stalk } 80 \% \\
\text { 、 Bran } 20 \%\end{array}$ & $35 \%$ & Bacillus subtilis、Saccharomyces cerevisiae、Bifidobacterium longum \\
\hline $\mathrm{D}$ & $\begin{array}{l}\text { Corn stalk } 80 \% \\
\text { 、 Bran } 20 \%\end{array}$ & $35 \%$ & Bacillus subtilis、Saccharomyces cerevisiae、Lactobacillus casei \\
\hline $\mathrm{E}$ & $\begin{array}{l}\text { Corn stalk } 80 \% \\
\text { Bran } 20 \%\end{array}$ & $35 \%$ & Bacillus subtilis、Saccharomyces cerevisiae, Lactobacillus rhamnosus \\
\hline $\mathrm{F}$ & $\begin{array}{l}\text { Corn stalk } 80 \% \\
\text { Bran } 20 \%\end{array}$ & $35 \%$ & $\begin{array}{l}\text { Bacillus subtilis、Saccharomyces cerevisiae、Lactobacillus plantarum、 } \\
\text { Lactobacillus acidophilus、Bifidobacterium longum、Lactobacillus casei } \\
\text { 、Lactobacillus rhamnosus }\end{array}$ \\
\hline
\end{tabular}




\section{Results and Discussion}

\section{Primer Specificity Verification}

The strains added in this study included Lactobacillus plantarum, Lactobacillus acidophilus, Bifidobacterium longum, Lactobacillus casei and Lactobacillus rhamnosus, and the primer specificity was verified after the primer crossing of these five strains. The results were shown in
Figure 1. Lactobacillus plantarum, Lactobacillus acidophilus, Bifidobacterium longum, Lactobacillus casei and Lactobacillus rhamnosus had specific amplification at 211 bp, 231 bp, 231 bp, 133 bp and 317 bp, respectively, while other bacteria had no specific amplification in this region. The above results indicate that the primers used in this experiment can specifically identify the fermentation flora in this experiment.

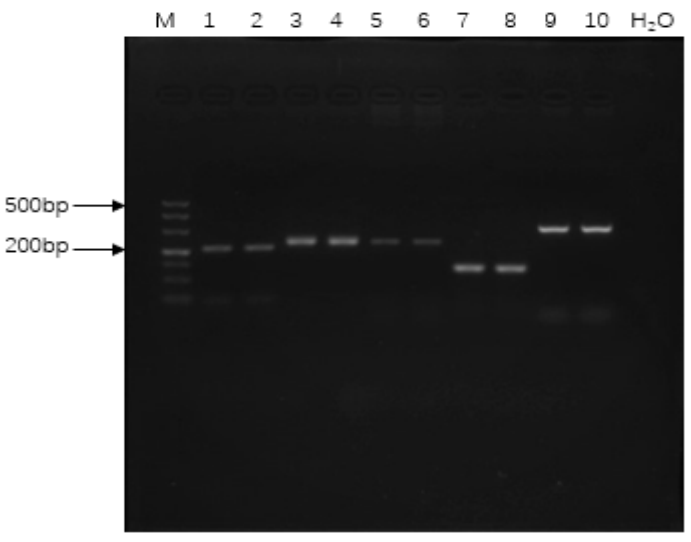

(a)

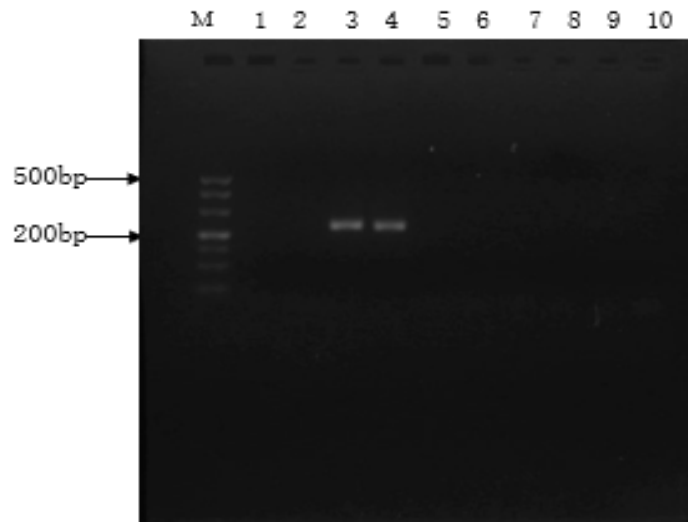

(c)

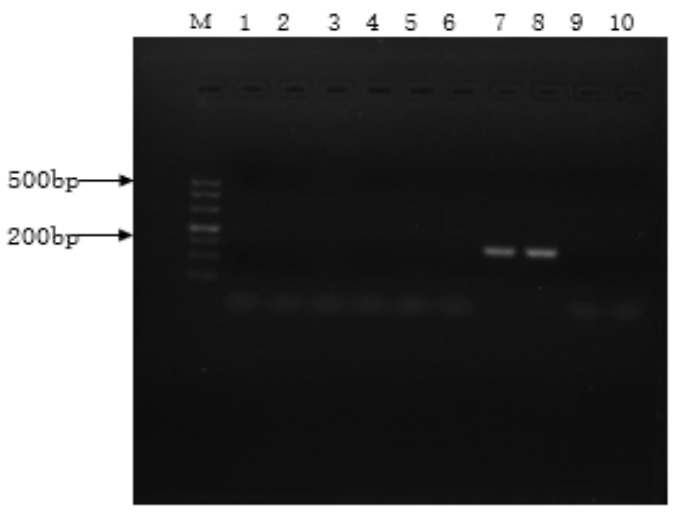

(e)

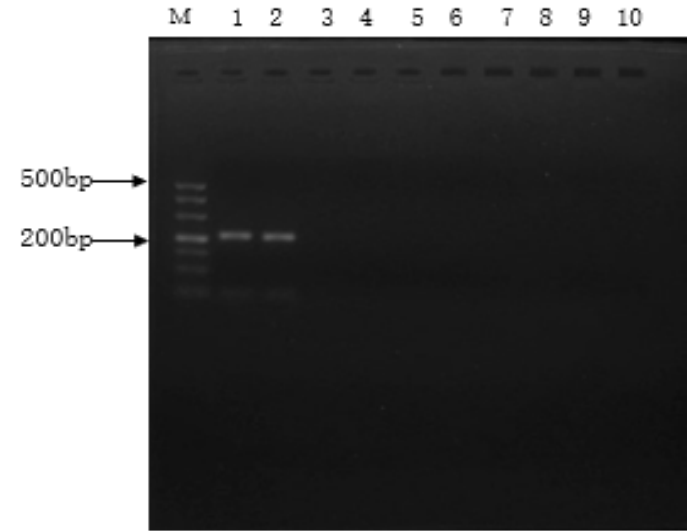

(b)

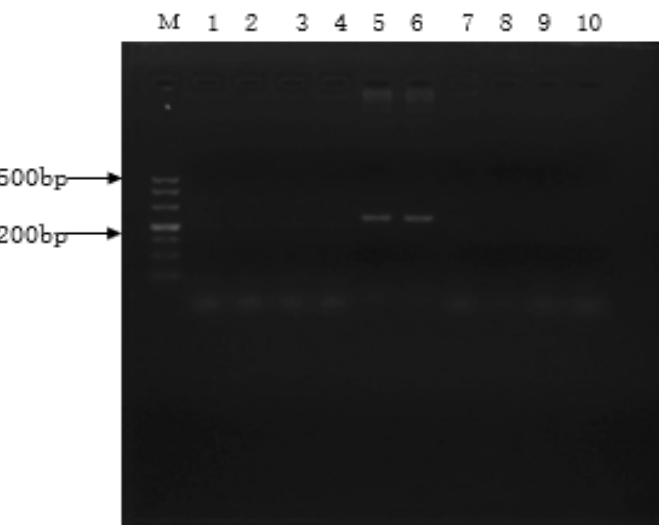

(d)

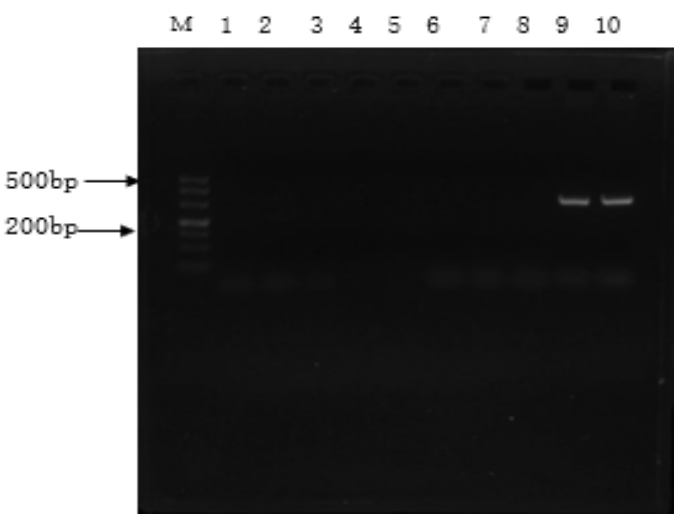

(f)

Figure 1. Primer-specific validation map of anaerobic probiotics 
(a) M is DNA Marker, 500 bp, 400 bp, 300 bp, 200 bp, $150 \mathrm{bp}, 100 \mathrm{bp}, 50 \mathrm{bp}$ from top to bottom, lanes 1 and 2 are Lactobacillus plantarum, lanes 3 and 4 are Lactobacillus acidophilus, 5 Lane 6 are Bifidobacterium longum, lanes 7 and 8 are Lactobacillus casei, lanes 9 and 10 are Lactobacillus rhamnosus (b) Lactobacillus plantarum primer-specific primer-specific validation Saccharomyces cerevisiae primer-specific validation (d)

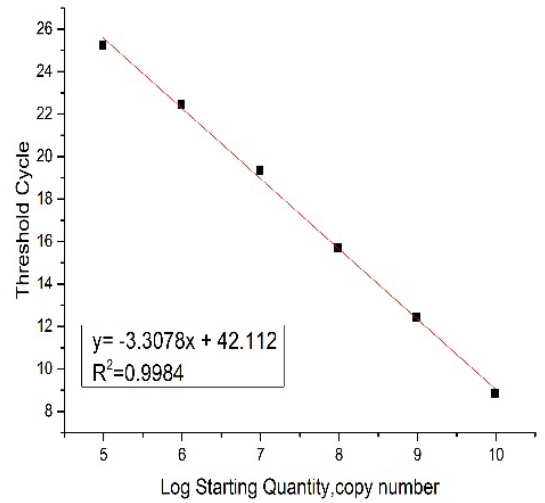

(a)

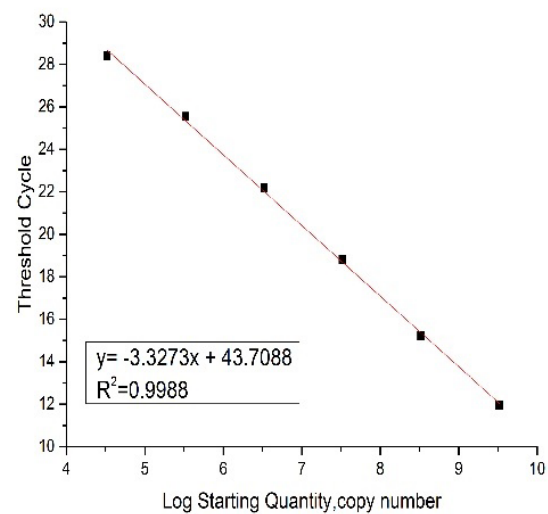

(c)
Bifidobacterium longum primer-specific validation (e) Lactobacillus casei primer-specific validation Lactobacillus rhamnosus primer-specific validation

\section{Establishment of Standard Curve}

As for the standard curves of the five kinds of lactic acid bacteria, the correlation coefficient $\mathrm{R}^{2}$ is all greater than 0.99 , which can be used as the standard for the detection of the test samples. See Figure 2 for specific standard curves.

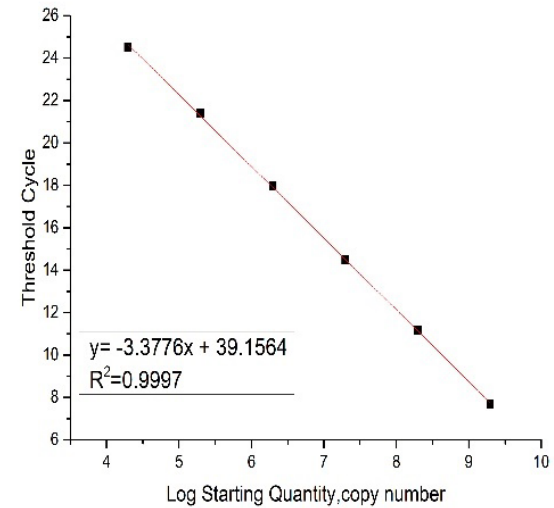

(b)

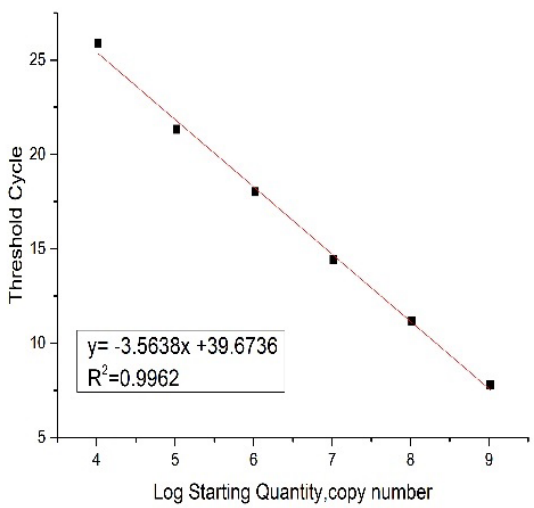

(d)

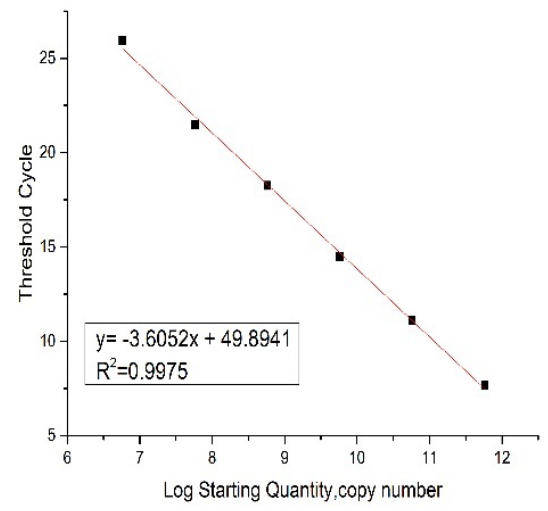

(e)

Figure 2 Standard Curve 
(a)Lactobacillus plantarum standard curve (b) Lactobacillus acidophilus standard curve (c) Bifidobacterium longum standard curve (d) Lactobacillus casei standard curve (e) Lactobacillus rhamnosus standard curve

\section{Melting Curve}

The specificity of the primers was further verified by the analysis of the melting curve. The melting curves of the

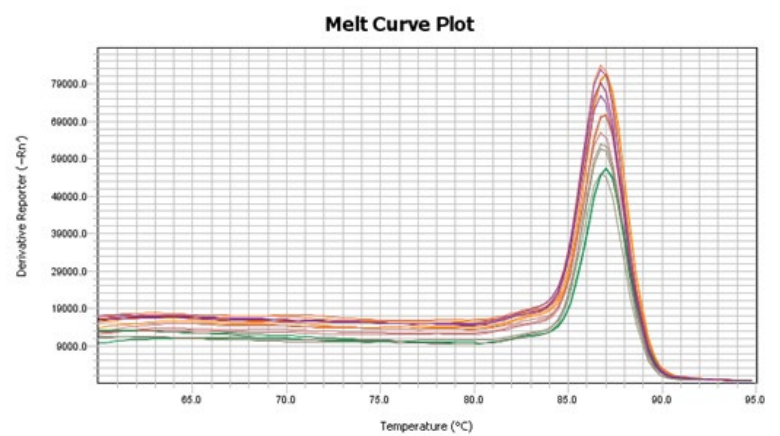

(a)

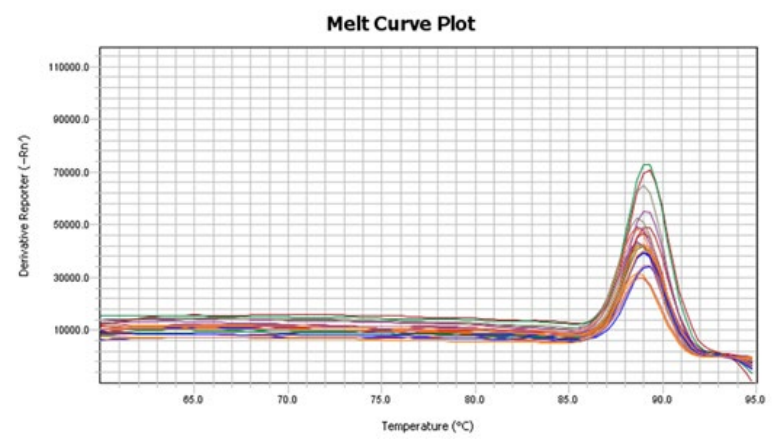

(c) five strains were all unimodal, indicating that the amplification products were single without the generation of non-target bands and dimers. This was also confirmed by agarose gel electrophoresis, as shown in Figure 3.

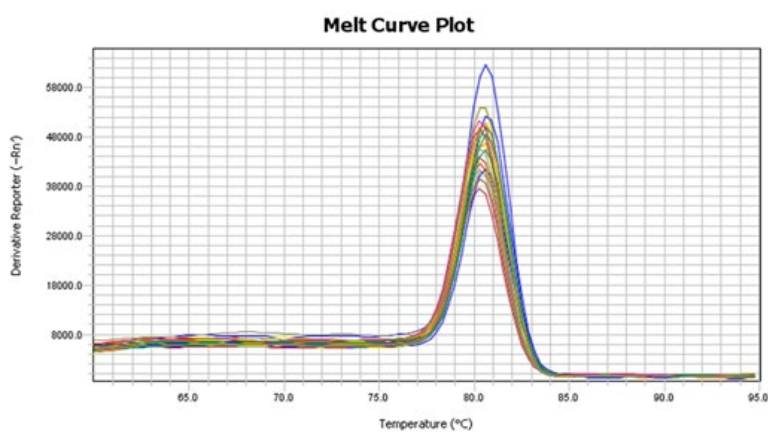

(b)

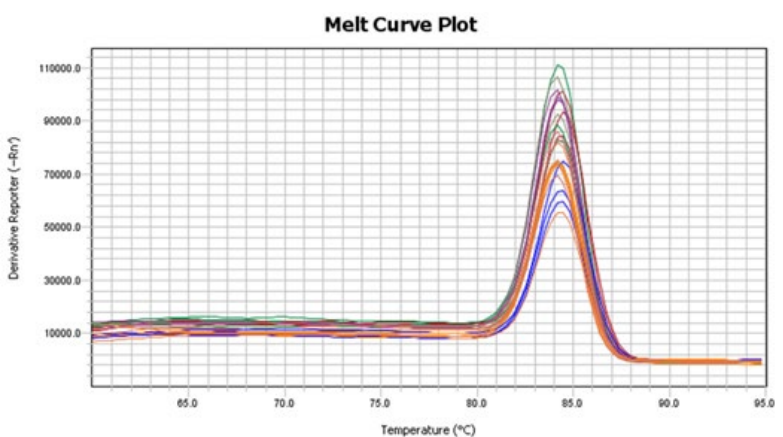

(d)

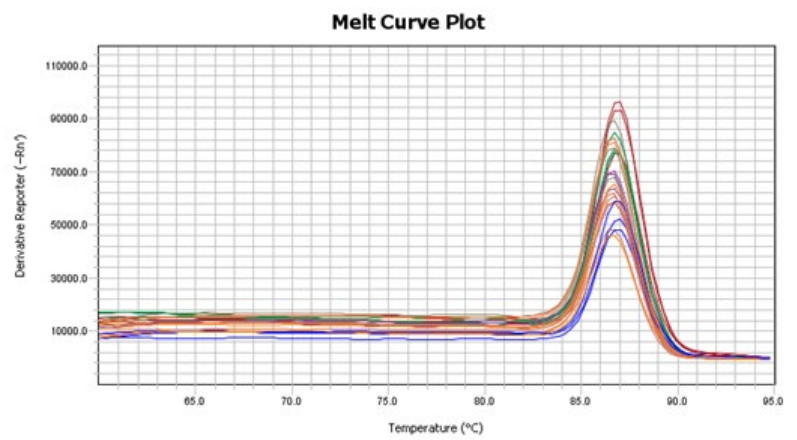

(e)

Figure 3 Standard Curve

(a)Lactobacillus plantarum standard curve (b) Lactobacillus acidophilus standard curve (c) Bifidobacterium longum standard curve (d) Lactobacillus casei standard curve (e) Lactobacillus rhamnosus standard curve

\section{Changes of Lactic Acid Bacteria during Stepwise Fermentation}

As can be seen from Figure $\underline{4}$, in general, the number of Lactobacillus plantarum in sample $\mathrm{F}$ is higher than that in sample $A$, which peaks on the $7^{\text {th }}$ day of mixed fermentation. The number of 
Lactobacillus plantarum in sample A $\left(3.09 \times 10^{7}\right.$ $\mathrm{CFU} / \mathrm{g})$ is slightly smaller than that in sample $\mathrm{F}$ (4.89 $\times 10^{7} \mathrm{CFU} / \mathrm{g}$ ) after fermenting one day, and the number of Lactobacillus plantarum in sample $\mathrm{F}$ was slightly higher in the middle and late stages of fermentation.

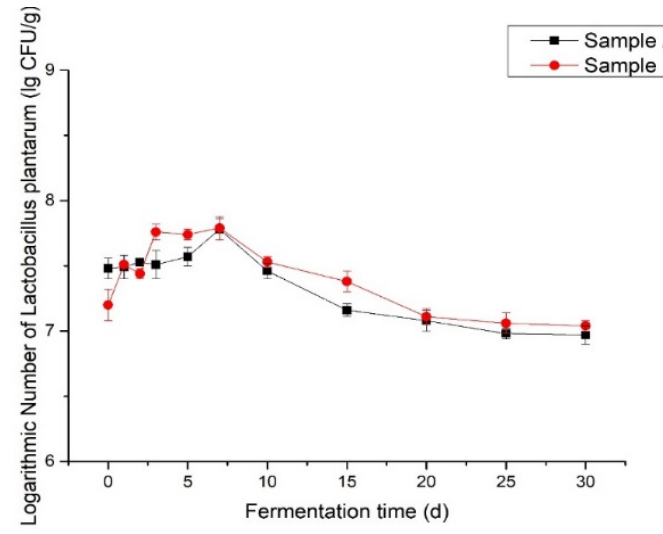

Figure 4 Number changes of Lactobacillus plantarum during step fermentation of biological feed Sample A: Fermentation with Lactobacillus plantarum alone; Sample F: Five lactic acid bacteria were added simultaneously for fermentation

As can be seen from figure $\underline{5}$, the number of Lactobacillus acidophilus in sample B is larger than that in sample F; the maximum number of Lactobacillus acidophilus in sample B appears on the third day $\left(1.17 \times 10^{7}\right.$ $\mathrm{CFU} / \mathrm{g}$ ), and the peak number of Lactobacillus acidophilus in sample $\mathrm{F}$ appears on the seventh day $\left(6.46 \times 10^{6} \mathrm{CFU} / \mathrm{g}\right)$. According to the figure, the two groups of bacteria tend to be the consistent after 25-30 days, and even the sample $F$ is slightly higher.

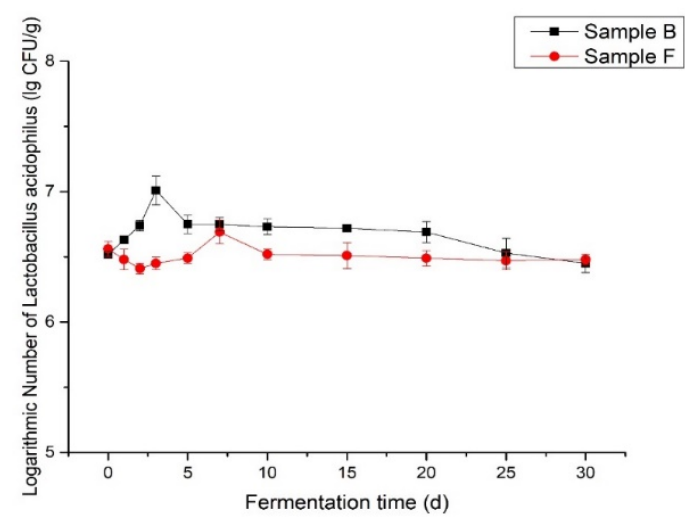

Figure 5 Number changes of Lactobacillus acidophilus during step fermentation of biological feed Sample B: Fermentation with Lactobacillus acidophilus alone; Sample F: Five lactic acid bacteria were added simultaneously for fermentation

As can be seen from figure $\underline{6}$, in the early stage of fermentation, the number in sample $C$ is generally larger than the number of Bifidobacterium longum in sample $\mathrm{F}$.
After 15 days of fermentation, the number of Bifidobacterium longum in sample $\mathrm{F}$ is larger, and the maximum value appears on the $7^{\text {th }}$ day $\left(1.69 \times 10^{8} \mathrm{CFU} / \mathrm{g}\right)$. This indicates that five kinds of lactic acid bacteria are fermented at the same time, and the number of Bifidobacterium longum did not decrease significantly. The results showed that the simultaneous addition of five lactic acid bacteria promoted the growth of Bifidobacterium longum, the peak value of sample $\mathrm{C}$ appeared on the third day $\left(5.49 \times 10^{8} \mathrm{CFU} / \mathrm{g}\right)$, then decreased slowly, and the number of Bifidobacterium longum was maintained at $10^{7}$ orders of magnitude.

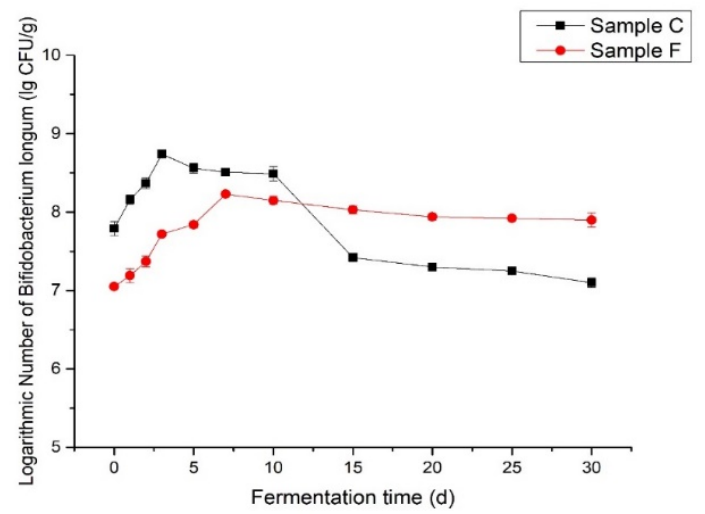

Figure 6 Number changes of Bifidobacterium longum during step fermentation of biological feed

Sample C: Fermentation with Bifidobacterium longum alone; Sample F: Five lactic acid bacteria were added simultaneously for fermentation

As shown in Figure $\underline{7}$, the number of Lactobacillus casei in sample $\mathrm{F}$ is generally higher than that of Lactobacillus casei in sample D, indicating that other bacteria begin to compete, and substances produced in the middle and late stages have synergistic or promoting effects on Lactobacillus casei. The maximum value of sample D appeared earlier and reached its maximum value $\left(4.68 \times 10^{7}\right.$ $\mathrm{CFU} / \mathrm{g}$ ) on the second day of fermentation, and the number of Lactobacillus casei in sample $\mathrm{F}$ reached the maximum on the $7^{\text {th }}$ day of mixed fermentation $\left(3.98 \times 10^{7} \mathrm{CFU} / \mathrm{g}\right)$.

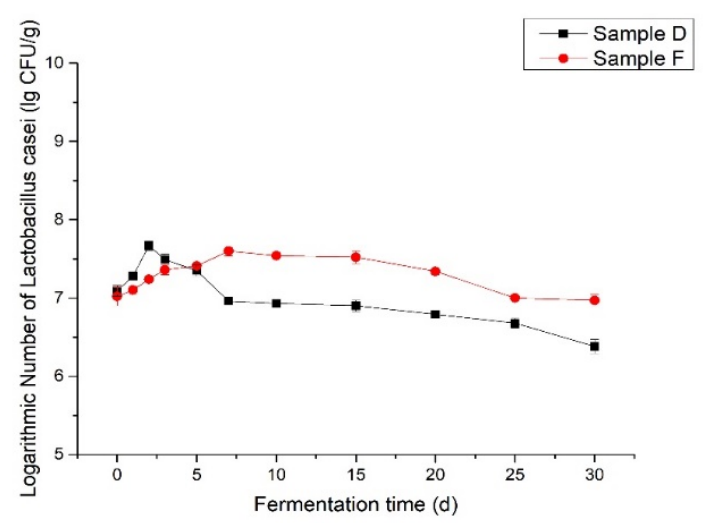

Figure 7 Number changes of Lactobacillus casei during step fermentation of biological feed 
Sample D: Fermentation with Lactobacillus casei alone; Sample F: Five lactic acid bacteria were added simultaneously for fermentation

As can be seen from Figure $\underline{8}$, in the initial stage of fermentation, the amount of Lactobacillus rhamnosus in sample $\mathrm{E}$ is larger than the number of Lactobacillus rhamnosus in sample $\mathrm{F}$, and sample $\mathrm{E}$ reaches its maximum value $\left(5.62 \times 10^{8} \mathrm{CFU} / \mathrm{g}\right)$ on the fifth day of fermentation. Sample F reached a maximum on the $7^{\text {th }}$ day of mixed fermentation $(3.16$ $\times 10^{8} \mathrm{CFU} / \mathrm{g}$ ). In general, the evolution trend of the amount of bacteria was similar, and the fermentation was almost the same on the $30^{\text {th }}$ day.

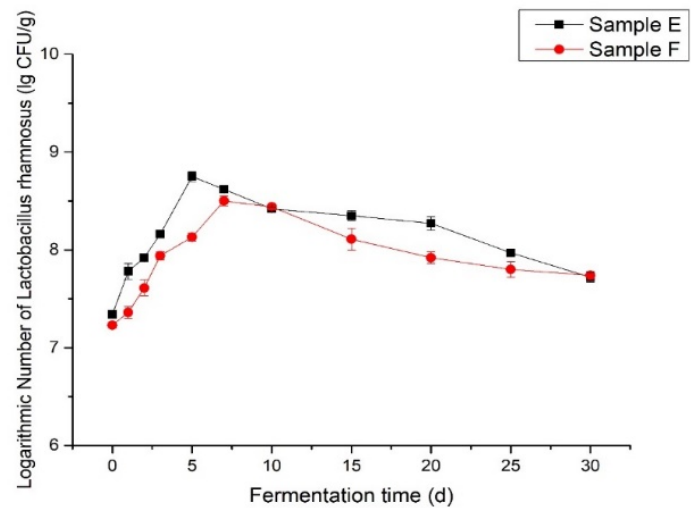

Figure 8 Number changes of Lactobacillus rhamnosus during step fermentation of biological feed

Sample E: Fermentation with Lactobacillus rhamnosus alone; Sample F: Five lactic acid bacteria were added simultaneously for fermentation

\section{Conclusion}

In this chapter, the quantitative analysis of five kinds of lactic acid bacteria, Lactobacillus plantarum, Lactobacillus acidophilus, Bifidobacterium longum, Lactobacillus casei and Lactobacillus rhamnosus, in the fermentation process of corn stalk bio-feed was carried out by fluorescence quantitative PCR. The results showed that the maximum value of lactic acid bacteria appeared in the $7^{\text {th }}$ day of mixed fermentation. Adding five kinds of lactic acid bacteria at the same time, After seven days of fermentation, it can significantly increase the total bacterial content, and the number of bacterium in mixed fermentation is generally close to that measured by single fermentation. There are slightly more bacteria in the middle and later stages of mixed fermentation, which indicates that the five kinds of lactic acid bacteria have more application value in cofermentation.

\section{Acknowledgements}

This study was financially supported by the Open Funding Project of the State Key Laboratory of
Biochemical Engineering, China (2018KF-02), and the Key Research and Development Program (Social Development) of Zhenjiang City SH2020021).

\section{Compliance with Ethical Standards}

Conflict of interest

The authors declared no conflict of interest.

\section{References}

1. Borshchevskaya, L. N., A. N. Kalinina, and S. P. Sineokii. (2013). Design of a PCR test based on the gyrA gene sequence for the identification of closely related species of the Bacillus subtilis group. Applied Biochemistry and Microbiology 49 (7):646-655.

2. de Almeida, A. A., S. S. Nakamura, A. Fiorini, A. B. Grisolia, T. I. E. Svidzinski, and K. M. P. de Oliveira. (2015). Genotypic variability and antifungal susceptibility of Candida tropicalis isolated from patients with candiduria. Revista Iberoamericana De Micologia 32 (3):153-158.

3. Elsanhoty, R. M., A. G. Ghonamy, N. A. ElAdly, and M. F. Ramadan. (2017). Impact of Lactic Acid Bacteria and Bifidobacterium on the Survival of Bacillus Subtilus during Fermentation of Wheat Sourdough. Journal of Food Processing and Preservation 41(4).

4. Fontana, A., C. Zacconi, and L. Morelli. (2018). Genetic Signatures of Dairy Lactobacillus casei Group. Frontiers in Microbiology 9.

5. Giraffa, G., N. Chanishvili, and Y. Widyastuti. (2010). Importance of lactobacilli in food and feed biotechnology. Research in Microbiology 161 (6):480-487.

6. Gueimonde, M., S. Tolkko, T. Korpimaki, and S. Salminen. (2004). New real-time quantitative PCR procedure for quantification of bifidobacteria in human fecal samples. Applied and Environmental Microbiology 70 (7):41654169.

7. Guo, C. F., S. Zhang, Y. H. Yuan, J. Y. Li, and T. L. Yue. (2018). Bile Salt Hydrolase and SLayer Protein are the Key Factors Affecting the Hypocholesterolemic Activity of Lactobacillus casei-Fermented Milk in Hamsters. Molecular Nutrition \& Food Research 62 (24).

8. Heo, W., E. S. Lee, H. T. Cho, J. H. Kim, J. H. Lee, S. M. Yoon, H. T. Kwon, S. Yang, and Y. J. Kim. (2018). Lactobacillus plantarum LRCC 5273 isolated from Kimchi ameliorates dietinduced hypercholesterolemia in C57BL/6 mice. Bioscience Biotechnology and Biochemistry 82 (11):1964-1972. 
9. Jangra, S., R. K. Sharma, R. Pothuraju, and G. Bhakri. (2019). Milk fermented with Lactobacillus casei NCDC19 improves high fat and sucrose diet alters gene expression in obese mice. International Dairy Journal 90:15-22.

10. Lan, R. X., and I. H. Kim.( 2019). Effects of Bacillus licheniformis and Bacillus subtilis complex on growth performance and faecal noxious gas emissions in growing-finishing pigs. Journal of the Science of Food and Agriculture 99 (4):1554-1560.

11. Lee, J. M., W. J. Jang, M. T. Hasan, B. J. Lee, K. W. Kim, S. G. Lim, H. S. Han, and I. S. Kong. (2019). Characterization of a Bacillus sp. isolated from fermented food and its synbiotic effect with barley -glucan as a biocontrol agent in the aquaculture industry. Applied Microbiology and Biotechnology 103 (3):14291439.

12. Liu, B. Y., H. L. Huan, H. R. Gu, N. X. Xu, Q. Shen, and C. L. Ding. (2019a). Dynamics of a microbial community during ensiling and upon aerobic exposure in lactic acid bacteria inoculation-treated and untreated barley silages. Bioresource Technology 273:212-219.

13. Liu, Q., X. J. Li, C. C. Sun, Q. Y. Wang, H. L. Yao, W. Yang, Z. Zheng, S. T. Jiang, and X. F. Wu. (2019b). Effects of mixed cultures of Candida tropicalis and aromatizing yeast in alcoholic fermentation on the quality of apple vinegar. 3 Biotech 9 (4).

14. Makino, H., J. Fujimoto, and K. Watanabe. (2010). Development and evaluation of a realtime quantitative PCR assay for detection and enumeration of yeasts of public health interest in dairy products. International Journal of Food Microbiology 140 (1):76-83.

15. Markkinen, N., O. Laaksonen, R. Nahku, R. Kuldjarv, and B. Yang. (2019). Impact of lactic acid fermentation on acids, sugars, and phenolic compounds in black chokeberry and sea buckthorn juices. Food Chemistry 286:204-215.
16. Mousavi, Z. E., and M. Mousavi. (2019). The effect of fermentation by Lactobacillus plantarum on the physicochemical and functional properties of liquorice root extract. Lwt-Food Science and Technology 105:164-168.

17. Ou, C. C., S. L. Lin, J. J. Tsai, and M. Y. Lin. (2011). Heat-Killed Lactic Acid Bacteria Enhance Immunomodulatory Potential by Skewing the Immune Response toward Th1 Polarization. Journal of Food Science 76 (5):M260-M267.

18. Sharma, A. N., S. Kumar, and A. K. Tyagi. (2018). Effects of mannan-oligosaccharides and Lactobacillus acidophilus supplementation on growth performance, nutrient utilization and faecal characteristics in Murrah buffalo calves. Journal of Animal Physiology and Animal Nutrition 102 (3):679-689.

19. Slacanac, V., J. Hardi, D. Curzik, H. Pavlovic, and M. Jukic. (2005). Production of antibacterial organic acids during the fermentation of goat and cow milk with Bifidobacterium longum BB-46. Acta Alimentaria 34 (3):277-285.

20. Yadav, R., D. K. Dey, R. Vij, S. Meena, R. Kapila, and S. Kapila. (2018). Evaluation of antidiabetic attributes of Lactobacillus rhamnosus MTCC: 5957, Lactobacillus rhamnosus MTCC: 5897 and Lactobacillus fermentum MTCC: 5898 in streptozotocin induced diabetic rats. Microbial Pathogenesis 125:454-462.

21. Yan, Y. H., X. M. Li, H. Guan, L. K. Huang, X. Ma, Y. Peng, Z. Li, G. Nie, J. Q. Zhou,W. Y. Yang, Y. Cai, and X. Zhang. (2019). Microbial community and fermentation characteristic of Italian ryegrass silage prepared with corn stover and lactic acid bacteria. Bioresource Technology 279:166-173.

22. Yao, K. Y., T. Z. Zhang, H. F. Wang, and J. X. Liu. (2018). Upgrading of by-product from beverage industry through solid-state fermentation with Candida utilis and Bacillus subtilis. Letters in Applied Microbiology 67 (6):557-563. 